\title{
Korean Red Ginseng Powder in the Treatment of Melasma: An Uncontrolled Observational Study
}

\author{
Margaret Song $^{1}$, Je-Ho Mun ${ }^{1}$, Hyun-Chang Ko ${ }^{1,2}$, Byung-Soo Kim ${ }^{1,2}$, and Moon-Bum Kim ${ }^{1,2^{*}}$ \\ ${ }^{1}$ Department of Dermatology, Pusan National University School of Medicine, Busan 602-739, Korea \\ ${ }^{2}$ Medical Research Institute, Pusan National University, Busan 602-739, Korea
}

\begin{abstract}
Exposure to the sun, ultraviolet radiation, and oxidative stress are the chief etiologic factors responsible for melasma. The ingredients of Korean red ginseng powder, which include ginsenoside and phenolic compounds, have antioxidative effects and reduce ultraviolet B-induced pigmentation. This study was designed to evaluate the effectiveness and safety of Korean red ginseng powder in patients with melasma. In 25 female patients, $3 \mathrm{~g}$ of Korean red ginseng powder was orally administered for a 24 week period. The level of pigmentation and erythema were determined and clinical improvement was evaluated by the melasma area and severity index (MASI), melasma quality of life scale (MELASQoL), and patient- and investigator-rated global improvement scale. After 24 weeks, the MASI score decreased from 8.8 to 5.6, and MELASQoL showed improvement in $91 \%$ of patients $(p<0.05)$. The mean level of pigmentation decreased from 184.3 to 159.7 and erythema levels decreased from 253.6 to $216.4(p<0.05)$. Additionally, $74 \%$ of the patients showed some improvement in both patient- and investigator-rated global improvement scales at week 24. Korean red ginseng powder was well tolerated by most of the patients. In conclusion, Korean red ginseng powder showed good tolerability and beneficial effects in patients with melasma. The use of Korean red ginseng would be counted as a useful adjunctive therapy for patients with melasma.
\end{abstract}

Keywords: Panax ginseng, Antioxidants, Melanosis, Ginsenosides, Korean red ginseng

\section{INTRODUCTION}

Melasma is a common acquired, symmetric hypermelanosis of the face, with highest prevalence in Asians and people of Hispanic origin. It is characterized by light to dark brown macules and patches predominantly on the sun exposed area. While the pathogenesis of melasma is not fully understood, exposure to the sun, pregnancy, intake of oral contraceptives, hormones such as estrogen and progesterone, use of cosmetics, administration of phototoxic and anticonvulsant drugs, and genetic influences are the predisposing factors. Among these factors, UV exposure is thought to be the main causative factor in the development of melasma [1,2].
Currently, the most widely used treatment modalities include application of sunscreen, topical hydroquinone in combination with tretinoin and/or corticosteroid, superficial chemical peeling, and laser therapy. Although various effective therapeutic modalities are in places, treatment of melasma is challenging because of its chronicity in its natural course and common recurrences. Therefore, new effective products for the treatment of melasma are still in demand.

Korean red ginseng powder, mainly composed of ginsenoside and phenolic compounds, has been shown to have effective in immunomodulatory, antioxidant, (c) This is an Open Access article distributed under the terms of the Creative Commons Attribution Non-Commercial License (http://creativecommons.org/licenses/by-nc/3.0/) which permits unrestricted non-commercial use, distribution, and reproduction in any medium, provided the original work is properly cited.
Received 03 Nov. 2010, Revised 30 Mar. 2011, Accepted 05 Apr. 2011

*Corresponding author

E-mail: drkmp@hanmail.net

Tel: +82-51-240-7338, Fax: +82-51-245-9467 
anti-aging, and anti-inflammatory activities [3-8]. Ginsenoside prevents UVB-induced intracellular increase of reactive oxygen species (ROS), while the phenol compounds inhibit tyrosinase in melanin synthesis [9-12].

We assessed the effectiveness of Korean red ginseng powder as a treatment modality for melasma by using the melasma area and severity index (MASI), mexameter (Courage \& Khazaka Electronic, Cologne, Germany), melasma quality of life, and global improvement scale. The general safety and tolerability of Korean red ginseng powder was also evaluated in patients with melasma.

\section{MATERIALS AND METHODS}

\section{Patients}

Twenty-five healthy female patients between 20 and $60 \mathrm{yr}$ of age, who were clinically diagnosed with melasma by dermatologists, were voluntarily enrolled in an open-label, prospective clinical study. The study was approved by the Pusan National University Institutional Review Board, and all the patients gave written informed consent. The exclusion criteria included the use of topical hydroquinone or tretinoin by the patient within 3 months before the study and a history of chemical peeling, microdermabrasion, or laser therapy within 9 months before the study. Patients who were pregnant, lactating, or planning a pregnancy were also excluded.

Patients were given $1 \mathrm{~g}$ of Korean red ginseng powder after each meal, 3 times a day (total daily dose of 3 g) for 24 weeks. The effectiveness and tolerability were evaluated at baseline, and at weeks 4, 8, 12, and 24. For enhancing the compliance of the patients, mobile phone text message was used before each hospital visit. All the patients were provided with a broad-spectrum sunscreen that they were asked to apply throughout the study period. They were also instructed to avoid exposure to the sun.

\section{Assessment of effectiveness and tolerability}

The MASI, mexameter measurements, and melasma quality of life scale (MELASQoL) results were recorded at each visit by 3 dermatologists (MS, JHM, and MBK). The global improvement scale was evaluated by both the patient and the investigators (MS, JHM, and MBK). A Polaroid photograph of the macule was marked to delineate a reference point for subsequent mexameter measurements at the initial visit and digital photographs were taken from the front, left and right oblique (45 degree) view during each visit.

The MASI is an index modified by Kimbrough-Green et al. [13] to more accurately quantify the severity of melasma throughout the treatment. The MASI is calculated on the basis of three variables: area (A) of involvement, darkness (D) of melasma, and homogeneity $(\mathrm{H})$ of pigmentation. The forehead (F), right malar region (MR), left malar region (ML), and chin (C) correspond to $30 \%$, $30 \%, 30 \%$, and $10 \%$ of the total face, respectively. The area of involvement in each of these 4 areas is given a numerical value from 0 to 6 ( 0 , no involvement; $1,0-9 \%$; $2,10-29 \%$; 3, 30-49\%; 4, 50-69\%; 5, 70-89\%; 6, 90$100 \%)$. The darkness and homogeneity of the macules and patches are rated on a scale of 0 to $4(0$, absent; 1 , slight; 2, mild; 3, marked; and 4, maximum) compared to normal skin. The MASI is obtained by the following equation; $\mathrm{MASI}=0.3(\mathrm{DF}+\mathrm{HF}) \mathrm{AF}+0.3(\mathrm{DMR}+$ $\mathrm{HMR}) \mathrm{AMR}+0.3(\mathrm{DML}+\mathrm{HML}) \mathrm{AML}+0.1(\mathrm{DC}+\mathrm{HC})$ AC. The total index can range from 0 to 48 .

The mexameter provides a reproducible and sensitive estimate of the content of melanin (pigment) and hemoglobin (erythema) and has an accuracy of $\pm 5 \%$ [14]. The values on the mexameter range from 1 to 1,000 , with 1 representing white and 1,000 representing black.

The MELASQoL is a disease-specific health-related quality-of-life instrument, which identifies the most impaired areas of a melasma patient's life. The MELASQoL consists of 10 questions and score ranges from 7 to 70 , with high score indicating a worse quality of life [15]. Global improvement was rated on a 5-point semiquantitative scale ( 0 , no change; 1 , slight improvement; 2 , moderate improvement; 3 , obvious improvement; and 4 , marked improvement). Tolerability was assessed on a 4-point scale of nausea, vomiting, diarrhea, hyperactivity, and sedation: 0 , none; 1 , mild; 2 , moderate and 3 , severe. Patients were also asked about any other adverse events that they experienced in the course of the study.

\section{Statistical analysis}

The statistical analysis was carried out using a Student's $t$-test for parametric data and Wilcoxon sign tests for non-parametric data. All the tests were 2-sided. A $p$ value $<0.05$ was considered statistically significant.

\section{RESULTS}

\section{Demographic features}

Twenty-five female patients between 29 and $56 \mathrm{yr}$ of age (mean, $43.2 \mathrm{yr}$ ) were enrolled in the study. Twentythree out of 25 patients completed the 24-wk study period. One patient withdrew from the study shortly after the initial visit for personal reasons and another dropped 
out because she experienced mild nausea, which did not require additional treatment. The second patient experienced gastrointestinal discomfort and nausea 3 weeks after the oral intake of Korean red ginseng powder, which continued for several days, but resolved soon after the administration of Korean red ginseng powder was stopped.

Demographic data are given in Table 1 . The mean duration of melasma in the patients before the study was $9.3 \mathrm{yr}$ (range, 0.5 to $25 \mathrm{yr}$ ). The main clinical pattern of melasma was centrofacial, followed by malar and mandibular.

\section{Effectiveness analysis}

The MASI score, the level of pigmentation and erythema, the MELASQoL score at initial visit and week 24 were demonstrated in Table 2 . The mean \pm SD MASI score at the initial visit was $8.76 \pm 6.56$, and it progressively decreased to $5.49 \pm 3.93$ at week 24 , with a $33.83 \%$ reduction (Fig. 1). The mean mexameter reading of pigmentation and erythema reduced gradually (Fig. 2). The mean level of pigmentation at the baseline was $184.27 \pm 52.39$ and decreased to $159.67 \pm 44.52$ at 24 weeks. Similarly, the mean level of erythema decreased from $253.58 \pm 53.88$ to $216.43 \pm 42.70,24$ wk after the

Table 1. Demographics of patients

\begin{tabular}{lc}
\hline \multicolumn{1}{c}{ Variables } & $\begin{array}{c}\text { Patients }(\%) \\
(n=23)\end{array}$ \\
\hline Fitzpatrick skin type & $9(39)$ \\
III & $11(48)$ \\
IV & $3(13)$ \\
V & \\
Clinical patterns of melasma & $15(65)$ \\
Centrofacial & $8(35)$ \\
Malar & $0(0)$ \\
Mandibular & $12(52)$ \\
History of melasma in first degree relative & \\
Aggravating factor & $11(48)$ \\
Sun exposure & $7(30)$ \\
Pregnancy & $1(4)$ \\
Oral contraceptives & $0(0)$ \\
Cosmetics &
\end{tabular}

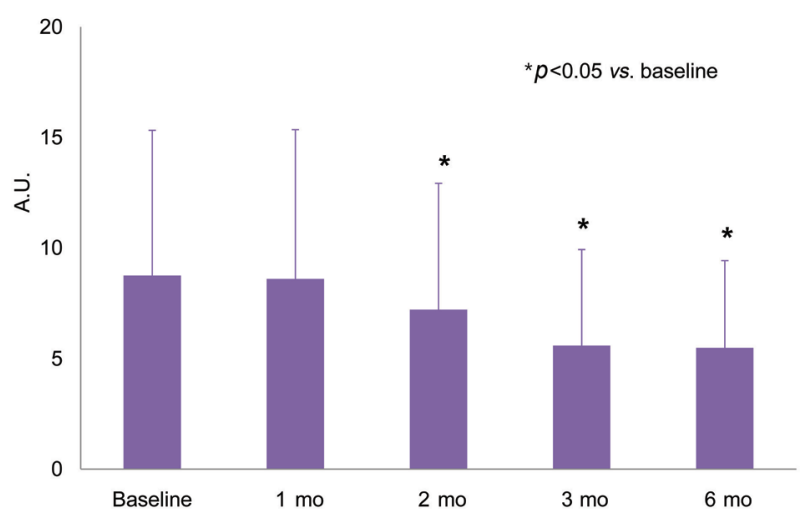

Fig. 1. Improvement in the melasma area and severity index.

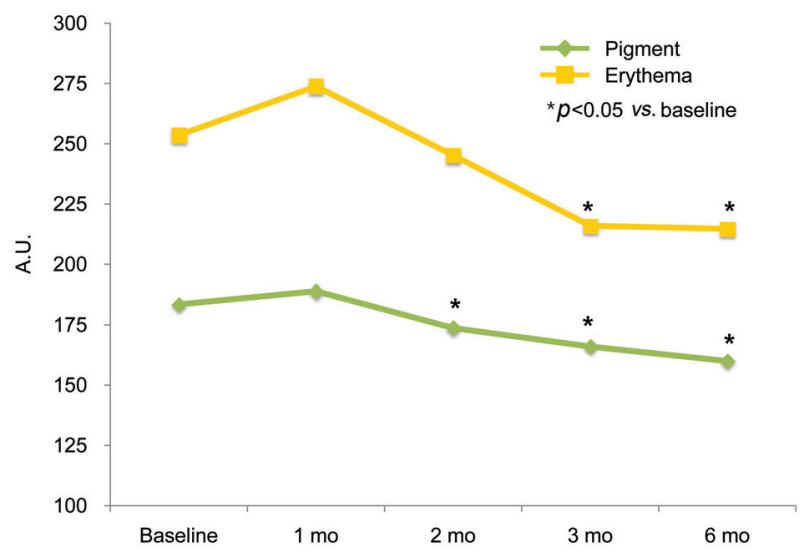

Fig. 2. Improvement of mean mexameter reading of pigmentation and erythema.

treatment. The decrease in the levels of pigmentation and erythema was statistically significant after week 8 and week 12 , respectively when compared to the initial levels. Fig. 3 shows noticeable improvement before and $24 \mathrm{wk}$ after the intake of Korean red ginseng powder in female patients.

Initially, the mean MELASQoL score was $46.57 \pm$ 12.71 , and it decreased to $31.96 \pm 13.83$ on week 24 . The scores on both the patient- and investigator-rated global improvement scales revealed that 17 patients showed some improvement and 6 patients showed none at week 24 (Fig. 4). The investigator global evaluation showed obvious improvement in 2 patients $(9 \%)$, moderate im-

Table 2. MASI score, level of pigmentation and erythema, MELASQoL score at initial visit and week 24

\begin{tabular}{lcccc}
\hline Variables & MASI & Level of pigmentation & Level of erythema & MELASQoL \\
\hline Initial visit & $8.76 \pm 6.56$ & $184.27 \pm 52.39$ & $253.58 \pm 53.88$ & $46.57 \pm 12.71$ \\
Week 24 & $5.49 \pm 3.93$ & $159.67 \pm 44.52$ & $216.43 \pm 42.70$ & $31.96 \pm 13.83$ \\
\hline
\end{tabular}

MASI, melasma area and severity index; MELASQoL, melasma quality of life scale. 

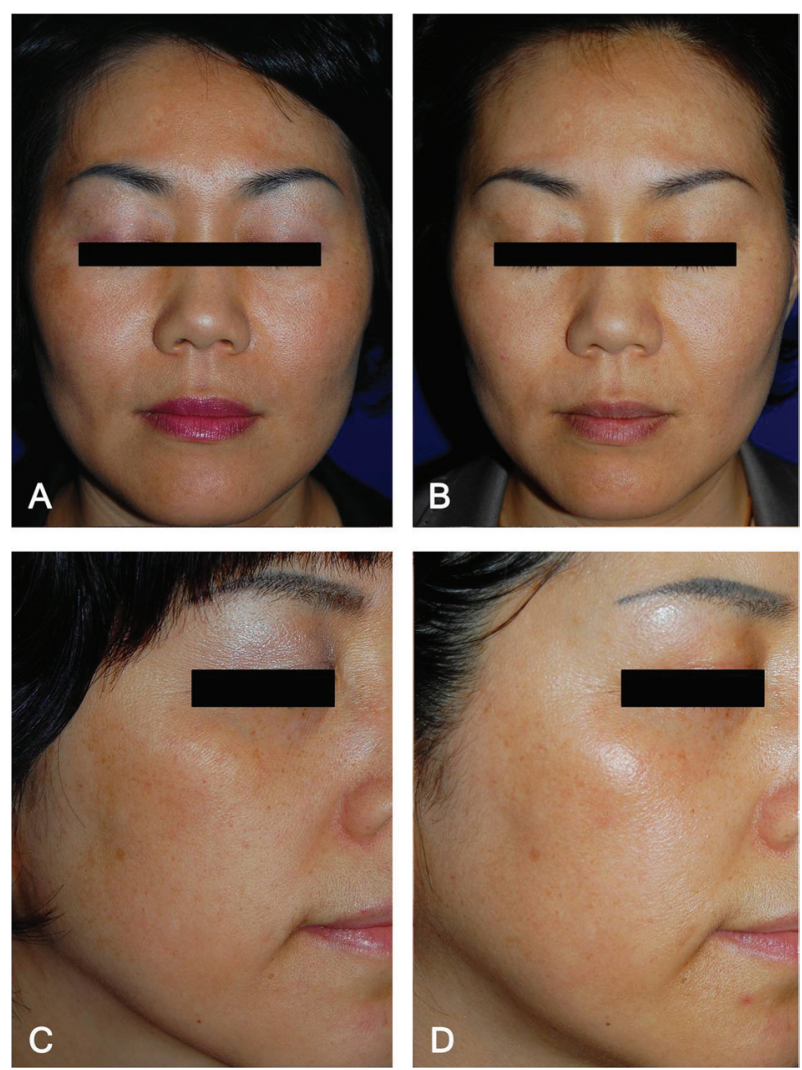

Fig. 3. Clinical improvement of 2 melasma patients; at initial visit $(A, C)$ and 24 weeks after $(B, D)$ oral administration of Korean red ginseng powder.

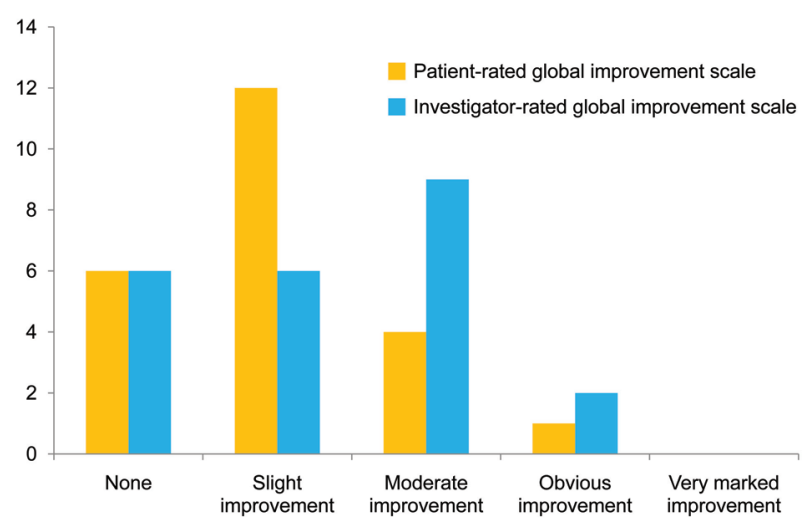

Fig. 4. Patient- and Investigator-rated global improvement scale at week 24.

provement in 9 patients (39\%), and slight improvement in 6 patients (26\%). There was no significant difference between the scores on patient- and investigator-rated global improvement scales.

\section{Tolerability}

During the 24-wk period, oral administration of Korean red ginseng powder was well tolerated by the patients with minimal adverse events. Only 1 patient complained of mild gastrointestinal discomfort and nausea, but the complaints were resolved soon after stopping the Korean red ginseng powder.

\section{DISCUSSION}

The target of melasma treatment includes protection from sunlight, inhibition of the melanocytic activity, inhibition of melanin synthesis, removal of melanin, and disruption of melanin granules $[1,2,16]$. Systemic drugs and natural products, including chloroquine, indomethacin, vitamin $\mathrm{C}$ and $\mathrm{E}, \beta$-carotene, fish oils, and green tea have shown to be effective as protective agents against UV radiation [16]. Other forms of oral therapy including administration of pycnogenol, a French maritime pine bark extract containing monomeric phenolic compounds and condensed flavonoids [17], and proanthocyanidinrich grape seed extract, have also shown to improve the melanin index and have good tolerability $[18,19]$. Such natural compounds work as antioxidants.

Histologically, melasma is characterized by epidermal hyperpigmentation and increased melanogenesis. Increased activity of the melanocytes and melanogenic enzymes overlying dermal changes are thought to be caused by solar radiation [20]. The role of UV radiation needs to be emphasized in the pathogenesis of melasma [20-22]. UV radiation activates protein kinase $\mathrm{C}$ directly and causes oxidative damage by generating free radicals [23]. It also induces ROS, which are likely play an important role in the development of the condition, in the skin and melanin biosynthesis in melanocytes and ROS. Furthermore, UV radiation indirectly acts on melanocytes by releasing of keratinocyte-derived factors, increasing melanization, and even inducing melanocyte proliferation [24-26]. The antioxidant defense systems such as ascorbic acid, glutathione, tocopherol, carotenoids, etc., have shown their effectiveness in the treatment of melasma.

Ginsenoside, the major active ingredient of Korean red ginseng, has been proven to have a wide range of pharmacological effects, such as immunomodulatory, antiaging, anti-inflammatory, and antioxidant activities [4,5]. Ginsenoside $\mathrm{F}_{1}$ protects $\mathrm{HaCaT}$ cells, in vitro, against UVB-induced apoptosis by maintaining constant level of Brn-3a and the corresponding inhibition of Bcl-2 downregulation [27]. The antioxidative effects of red ginseng have also been studied by activating melanocytes by UVB radiation in the epidermis of C57BL/6 mice by [28]. The number and size of DOPA-positive melanocytes have found to be significantly decreased in both 
peritoneally injected and topically applied red ginseng after the UVB radiation, suggesting that the red ginseng is an inhibitor of UVB-induced pigmentation because of its antioxidative effects $[29,30]$. Additionally, the numerous phenolic compounds in ginseng, such as esculetin, cinnamic acid, p-coumaric acid, quercetin, and maltol inhibit the activity of tyrosinase, which is a key enzyme of melanogenesis $[9,10,12]$.

There are other positive effects of red ginseng on the human skin. In vitro, ginsenoside $\mathrm{Rb}_{2}$ showed an antioxidative effect by decreasing UVB radiation-induced apoptotic sun burn cells and prevented the decrease of ATPase positive dendritic cells [30]. The administration of red ginseng could reduce the extent of skin damage caused by UVB radiation. Compound $\mathrm{K}$ in red ginseng enhances the expression of hyaluronan synthase 2 in human keratinocyte, and might prevent or improve age-dependent decrease of hyaluronic acid levels in human skin [31]. Red ginseng extract has been shown to have an antiwrinkle effect in hairless mice upon oral administration [11]. Lastly, Korean red ginseng, torilis fructus and corni fructus mixture (KTNG0345) have anti-wrinkle activity through the tumor necrosis factor- $\alpha$ mediated matrix metalloproteinase expression pathway [32].

The oral administration of red ginseng improved melasma in MASI, which was evident at $8 \mathrm{wk}$, and MASI slowly decreased throughout the 24 -wk period, with $33.83 \%$ reduction compared to the baseline. The mexameter reading of pigmentation and erythema showed statistically significant improvement at $8 \mathrm{wk}$ and $12 \mathrm{wk}$, respectively. Recent studies suggested that there was a connection between the number of vessels and cutaneous pigmentation and that the human melanocyte may be responding to angiogenic factors [33]. The melanocytes express functional vascular endothelial growth factor and the altered cutaneous vasculature and melanocytes influence the development of hyperpigmentation in the over-lying dermis, including in melasma [33,34]. Kim et al. [34] also found that there was a positive relationship between the number of vessels and the level of pigmentation in melasma patients. In this study, erythema decreased along with the pigmentation during the study period.

The clinical improvement of melasma had a positive impact on quality of life, such as mood, self-esteem, interaction with other people, etc. Overall, both the physician and patients documented an improvement in $74 \%$ of the patients. Korean red ginseng powder was tolerated by most of the patients, and only one patient had mild gastrointestinal discomfort and nausea, but it did not cause any severe adverse reaction in the central nervous system in any patient during the entire study period.

This study has three major limitations. First, there was no control group and that it was not blinded, because we were unable to find a suitable placebo to carry out double-blind randomized controlled studies required to confirm the test results. Second, unblinding of investigators may have increased risk of detection bias. Third, the effect of sunscreen for the treatment of melasma in this study had to be considered. Although positive outcomes were obtained from this study, lack of a control and blinding may limit the assurance of the positive outcome, and the result may have to be interpreted with caution. We would recommend further double blind randomized controlled study designs to confirm the efficacy of oral Korean red ginseng powder and topical products which include Korean red ginseng powder and/or ginsenoside to confirm its effect on melasma.

\section{ACKNOWLEDGEMENTS}

This study was supported by the 2008 grant from the Korean Society of Ginseng funded by Korean Ginseng Corporation.

\section{REFERENCES}

1. Grimes PE. Melasma. Etiologic and therapeutic considerations. Arch Dermatol 1995;131:1453-1457.

2. Gupta AK, Gover MD, Nouri K, Taylor S. The treatment of melasma: a review of clinical trials. J Am Acad Dermatol 2006;55:1048-1065.

3. Jang SK, Kim JH, Chung YS, Ahn DC, Kang MJ, Lee DG, Kim SH. An experimental study on the effect of immunopotential and the anticancer effect of red ginseng extract. Korean J Ginseng Sci 1994;18:151-159.

4. Wang Y, Wang BX, Liu TH, Minami M, Nagata T, Ikejima T. Metabolism of ginsenoside Rg1 by intestinal bacteria. II. Immunological activity of ginsenoside Rg1 and Rh1. Acta Pharmacol Sin 2000;21:792-796.

5. Chen XC, Zhu YG, Wang XZ, Zhu LA, Huang C. Protective effect of ginsenoside Rg1 on dopamine-induced apoptosis in PC12 cells. Acta Pharmacol Sin 2001;22:673-678.

6. Nam KY. Clinical applications and efficacy of Korean ginseng. J Ginseng Res 2002;26:111-131.

7. Choi JH, Oh DH. Effect of white and red ginseng extract on the immunological activities in lymphocytes isolated from sasang constitution blood cells. J Ginseng Res 2009; 33:33-39.

8. Kim EH, Rhee DK. Anti-oxidative properties of ginseng. 
J Ginseng Res 2009;33:1-7.

9. Kahn V, Ben-Shalom N. Effect of maltol on the oxidation of DL-DOPA, dopamine, N-acetyldopamine (NADA), and norepinephrine by mushroom tyrosinase. Pigment Cell Res 1997;10:139-149.

10. Lim JY, Ishiguro K, Kubo I. Tyrosinase inhibitory pcoumaric acid from ginseng leaves. Phytother Res 1999; 13:371-375.

11. Lee JH, Lee BS, Yang MS, Byun BS, Kim WG, Kim BH, Lee SJ. Prevention of photoaging and wrinkle formation in hairless mice dorsal skin by AP3-03. Korean J Food Sci Technol 2005;37:989-996.

12. Hwang EY, Kong YH, Lee YC, Kim YC, Yoo KM, Jo YO, Choi SY. Comparison of phenolic compounds contents between white and red ginseng and their inhibitory effect on melanin biosynthesis. J Ginseng Res 2006;30:8287.

13. Kimbrough-Green CK, Griffiths CE, Finkel LJ, Hamilton TA, Bulengo-Ransby SM, Ellis CN, Voorhees JJ. Topical retinoic acid (tretinoin) for melasma in black patients. A vehicle-controlled clinical trial. Arch Dermatol 1994;130:727-733.

14. Taylor S, Westerhof W, Im S, Lim J. Noninvasive techniques for the evaluation of skin color. J Am Acad Dermatol 2006;54(5 Suppl 2):S282-S290.

15. Balkrishnan R, McMichael AJ, Camacho FT, Saltzberg F, Housman TS, Grummer S, Feldman SR, Chren MM. Development and validation of a health-related quality of life instrument for women with melasma. Br J Dermatol 2003;149:572-577.

16. Piamphongsant T. Treatment of melasma: a review with personal experience. Int J Dermatol 1998;37:897-903.

17. Ni Z, Mu Y, Gulati O. Treatment of melasma with Pycnogenol. Phytother Res 2002;16:567-571.

18. Yamakoshi J, Otsuka F, Sano A, Tokutake S, Saito M, Kikuchi M, Kubota Y. Lightening effect on ultravioletinduced pigmentation of guinea pig skin by oral administration of a proanthocyanidin-rich extract from grape seeds. Pigment Cell Res 2003;16:629-638.

19. Yamakoshi J, Sano A, Tokutake S, Saito M, Kikuchi M, Kubota Y, Kawachi Y, Otsuka F. Oral intake of proanthocyanidin-rich extract from grape seeds improves chloasma. Phytother Res 2004;18:895-899.

20. Kang WH, Yoon KH, Lee ES, Kim J, Lee KB, Yim H, Sohn S, Im S. Melasma: histopathological characteristics in 56 Korean patients. Br J Dermatol 2002;146:228-237.

21. Horikoshi T, Nakahara M, Kaminaga H, Sasaki M, Uchiwa H, Miyachi Y. Involvement of nitric oxide in UVBinduced pigmentation in guinea pig skin. Pigment Cell Res 2000;13:358-363.
22. Ortonne JP, Arellano I, Berneburg M, Cestari T, Chan H, Grimes P, Hexsel D, Im S, Lim J, Lui H et al. A global survey of the role of ultraviolet radiation and hormonal influences in the development of melasma. J Eur Acad Dermatol Venereol 2009;23:1254-1262.

23. Peak JG, Woloschak GE, Peak MJ. Enhanced expression of protein kinase $\mathrm{C}$ gene caused by solar radiation. Photochem Photobiol 1991;53:395-397.

24. Kupper TS, Min K, Sehgal P, Mizutani H, Birchall N, Ray A, May L. Production of IL-6 by keratinocytes. Implications for epidermal inflammation and immunity. Ann N Y Acad Sci 1989;557:454-464.

25. Kondo S, Kono T, Sauder DN, McKenzie RC. IL-8 gene expression and production in human keratinocytes and their modulation by UVB. J Invest Dermatol 1993;101:690-694.

26. Eller MS, Ostrom K, Gilchrest BA. DNA damage enhances melanogenesis. Proc Natl Acad Sci U S A 1996;93:10871092.

27. Lee EH, Cho SY, Kim SJ, Shin ES, Chang HK, Kim DH, Yeom MH, Woe KS, Lee J, Sim YC et al. Ginsenoside F1 protects human $\mathrm{HaCaT}$ keratinocytes from ultraviolet-Binduced apoptosis by maintaining constant levels of Bcl2. J Invest Dermatol 2003;121:607-613.

28. Lee HJ, Kim SR, Kim JS, Moon CJ, Kim JC, Bae CS, Jang JS, Jo SK, Kim SH. The effect of red ginseng on epidermal melanocytes in ultraviolet B-irradiated mice. J Ginseng Res 2006;30:188-193.

29. Lee TK, Johnke RM, Allison RR, O'Brien KF, Dobbs LJ Jr. Radioprotective potential of ginseng. Mutagenesis 2005;20:237-243.

30. Lee HJ, Kim SR, Kim JS, Moon CJ, Kim JC, Bae CS, Jang JS, Jo SK, Kim SH. The effect of red ginseng on ultraviolet-B induced skin damages in mouse. J Ginseng Res 2006;30:194-198.

31. Kim S, Kang BY, Cho SY, Sung DS, Chang HK, Yeom MH, Kim DH, Sim YC, Lee YS. Compound K induces expression of hyaluronan synthase 2 gene in transformed human keratinocytes and increases hyaluronan in hairless mouse skin. Biochem Biophys Res Commun 2004;316: 348-355.

32. So SH, Lee SK, Hwang EI, Koo BS, Han GH, Chung JH, Lee MJ, Kim NM. Mechanism of Korean red ginseng and herb extracts (KTN0345) for anti-wrinkle activity. J Ginseng Res 2008;32:39-47.

33. Kim EJ, Park HY, Yaar M, Gilchrest BA. Modulation of vascular endothelial growth factor receptors in melanocytes. Exp Dermatol 2005;14:625-633.

34. Kim EH, Kim YC, Lee ES, Kang HY. The vascular characteristics of melasma. J Dermatol Sci 2007;46:111-116. 